\title{
Analisis Pengaruh Keterbukaan dan Audit Internal Terhadap Penerapan Good Corporate Governance Pada Perusahaan Daerah Air Minum (PDAM) Tirta Sakti Kerinci Tahun 2017
}

\author{
Maryanto \\ maryantoyanto@gmail.com
}

\begin{abstract}
Disclosure of information is an openness and honesty of information within a company that the government is responsible for its trusting resources in accordance with the laws and regulations in order to know openly the circumstances of a company based on the consideration that everyone has the right to know openly and thorough information. Disclosure of information and internal audit is an important factor in the implementation of good corporate governance. This study aims to determine the effect of information disclosure and internal audit on the implementation of good corporate governance in water utility company PDAM Tirta Sakti Kerinci Year 2017. Population and sample in this study are internal auditors who are in the Division of Internal Control Unit (SPI) working on PDAM Tirta Sakti Kerinci samples taken as many as 12 people. The sample in this research use purposive sampling technique. Based on the research that the authors do, show that There is a significant influence between the Public Information Disclosure Against the Application of Good Corporate Governance in Regional Water Company PDAM Tirta Sakti
\end{abstract}

Key words: Information Disclosure. internal audit and Good Corporate Governance

\section{PENDAHULUAN}

Keterbatasan komunikasi antara manajemen puncak dan lini operasi yang sedang berjalan tersebut tidak dapat menutup kemungkinan bahwa akan terjadinya praktekpraktek yang dapat membahayakan perusahaan seperti praktik korupsi, kolusi, dan nepotisme. Hal tersebut akan sulit untuk dideteksi, karena akan diketahui apabila adanya kebetulan atau suatu hal yang disengaja. Praktik ini juga merupakan ancaman yang berbahaya bagi perusahaan, karena tindakan tersebut memiliki efek terhadap risiko kerugian keuangan yang berakibat perusahaan itu dapat mengalami kebangkrutan.

Faktor yang dapat mencegah terjadinya praktek-praktek yang dapat membahayakan perusahaan, yaitu penerapan good corporate governance pada perusahaan. Istilah good corporate governance tersebut muncul terutama sejak adanya skandal international, seperti dalam kasus Enron dan WorldCom, dengan demikian good corporate governance tersebut bukan merupakan pola baru atau merupakan sebuah inovasi, tetapi merupakan suatu pertanggungjawaban kepada publik mengenai perkembangan yang ada.

Dalam upaya penerapan good corporate governance peran audit internal yang independen sangatlah penting dan audit Internal merupakan kegiatan pemastian dan konsultasi yang independen dan objektif yang dirancang untuk menambah nilai dan meningkatkan operasi organisasi. Audit Internal dapat membantu organisasi mencapai tujuan nya melalui pendekatan yang sistematik 
dan teratur untuk mengevaluasi dan efektifitas proses pengelolaan resiko pengendalian serta tata kelola.

Untuk mewujudkan pemerintahan yang bersih demi kemanfaatannya untuk orang banyak, kebebasan untuk mendapatkan informasi merupakan syarat kunci yang mesti dipenuhi oleh penyelenggara negara. Bahkan penyelenggara negara mesti aktif untuk menggalakkan partisipasi warga dalam mengakses sedemikian banyak informasi terkait dengan pengelolaan pemerintahan. Bila ini terjadi, maka kebebasan informasi untuk melawan korupsi dan sebagai perangkat politik warga untuk mengontrol penyelenggara negara telah menemui relevansinya. Dalam hal keterbukaan informasi, prilaku birokrasi mau tidak mau mesti menyelaras pada tuntutan dan partisipasi publik dalam hal memperoleh informasi.

Penerapan prinsip-prinsip good corvorate governance di PDAM akan terwujud efisiensi, kompetisi, pertumbuhan berkelanjutan, berpendapatan tinggi dan nilai perusahaan yang optimum. Dengan penerapan good corporate governance akan tercapai peningkatan kinerja pelayanan dan manajemen pada PDAM, seperti yang diharapkan. Untuk itu perusahaan daerah sudah sewajarnya agar menerapkan good corvorategovernance agar perusahaan dapat mencapai tujuanya yaitu turut serta dalam mensejahterakan masyarakat melalui fungsi-fungsi sosial seperti pelayanan pemberdayaan, pengembangan usaha bagi masyarakat agar lebih berkembang dan memperoleh keuntungan. Adapun tujuan dari penelitian ini adalah apakah terdapat pengaruh antara keterbukaan informasi dan audit internal terhadap penerapan good corporate governance pada perusahaan daerah air minum pdam tirta sakti kerinci tahun 2017 baik secara parsial dan simultan?

\section{METODE}

Penelitian ini menggunakan metode Penelitian Lapangan (Field Research), yaitu penelitian secara langsung ke tempat penelitian dengan maksud memperoleh data primer. Data primer ini di peroleh dengan cara :

1. Observasi, yaitu suatu teknik pengumpulan data dengan mengamati dan meninjau secara langsung ke perusahaan yang di teliti.

2. Kuesioner, yaitu lembar isian yang di dalamnya berisi pertanyaan dan pertanyaan yang dapat mengolah data kualitatif menjadi kuantitatif dengan pengujian hipotesis.

Populasi dalam penelitian ini adalah seluruh pegawai pada Perusahaan Air Minum PDAM Tirta Sakti Kerinci yang terdiri dari 61 orang. Penarikan sampel dilakukan dengan teknik purposive sampling yang memberi peluang yang sama bagi setiap anggota populasi untuk dipilih dan berdasarkan pertimbangan tertentu, maka sampel yang mewakili untuk penelitian tersebut adalah karyawan yang berhubungan dengan objek yang diteliti, yaitu karyawan Satuan Pengawasan Intern (SPI) yang berjumlah 12 orang.

\section{Regresi Linier Berganda}

Model regresi linier berganda berguna untuk memperoleh gambaran menyeluruh mengenai hubungan variabel dependen dengan variabel.

$\mathrm{Y}=\mathrm{a}+\mathrm{b}_{1} \mathrm{X}_{1}+\mathrm{b}_{2} \mathrm{X}_{2}+\mathrm{e}$ 
Keterangan : $\mathrm{Y}=$ Good Corporate Governance; $\mathrm{a}=$ Konstanta; $\mathrm{b}_{1}, \mathrm{~b}_{2}=$ Koefisien Regresi Variabel Bebas; $\mathrm{X}_{1}=$ Variabel Keterbukaan Informasi; $\mathrm{X}_{2} \quad=$ Variabel Audit Internal; $\mathrm{E}=$ Error Term

Untuk mengetahui peran audit internal dalam mwujudkan good corporate governance pada perusahaan daerah air minum (PDAM) Tirta Sakti Kerinci dapat digunakan rumus sebagai berikut:

$\mathrm{KD}=r^{2} \times 100 \%$

Keterangan : $\mathrm{KD}=$ Koefisien Determinasi; $r^{2}=$ Koefisien Korelasi

\section{Hipotesis}

Secara parsial:

$\mathrm{H}_{0} \mathrm{~b}_{1}=0$, Diduga tidak terdapat pengaruh antara keterbukaan informasi publik terhadap penerapan good corporate governance di Perusahaan Daerah Air Minum (PDAM) Tirta Sakti Kerinci.

$\mathrm{H}_{\mathrm{a}}: \mathrm{b}_{1} \neq 0$, Diduga terdapat pengaruh antara keterbukaan informasi publikTerhadap penerapan good corporate governance pada Perusahaan Daerah Air Minum (PDAM) Tirta Sakti Kerinci.

Ho:b2=0, Diduga tidak terdapat pengaruhantara audit internal terhadap penerapan good corporategovernance pada Perusahaan Daerah Air Minum (PDAM) Tirta Sakti Kerinci.

$\mathrm{H}_{\mathrm{a}}: \mathrm{b}_{2} \neq 0$, Diduga terdapat pengaruh antara audit internal terhadap penerapangood corporate governance pada Perusahaan Daerah Air Minum (PDAM) Tirta Sakti Kerinci.

Secara Simultan

$\mathrm{H}_{\mathrm{O}}$ : $\mathrm{r}=0$, Diduga tidak terdapat pengaruh antara Keterbukaan Informasi Publik dan Audit Internal terhadap penerapan good corporate governance pada Perusahaan Daerah
Air Minum PDAM Tirta Sakti Kerinci.

$\mathrm{H}_{\mathrm{a}}: \mathrm{r} \neq 0$, Diduga terdapat pengaruh antara Keterbukaan informasi publik dan Audit Internal terhadap penerapan good corporate governance pada Perusahaan Daerah Air Minum PDAM Tirta Sakti Kerinci.

\section{Uji t}

Pengeujian selanjutnya uji signifikansi yang berfungsi apabila peneliti ingin mencari makna hubungan variabel $\mathrm{X}$ terhadap $\mathrm{Y}$, maka di uji dengan uji signifikansi dengan menggunakan uji t.

$\mathrm{t}_{\text {hitung }}=\frac{r \sqrt{n-2}}{\sqrt{1+r^{2}}}$

Keterangan $: t_{\text {hitung }}=$ Nilai $\mathrm{t} ; \mathrm{r}=$ Nilai Korelasi; $\mathrm{n}=$ Jumlah Sampel

Distribusi (Tabel t) untuk $\alpha$ $=0,05$ dan derajat kebebasan $(\mathrm{dk}=\mathrm{n}$ - 2 ) kaidah keputusan : Apabila $\mathrm{t}_{\text {hitung }} \geq \mathrm{t}_{\text {tabel, }}$, maka Ho ditolak dan Ha

diterima artinya terdapar pengaruh yang signifikan antara keterbukaan informasi dan audit internal terhadap penerapan good corporate governance. Apabila $t_{\text {hitung }} \leq \mathrm{t}_{\text {tabel }}$,

maka Ha ditolak Ho diterima artinya tidak terdapat pengaruh yang signifikan antara keterbukaan informasi dan audit internal terhadap penerapan good corporate governance.

\section{Uji F}

Menurut Ghozali, (2001) Uji $\mathrm{F}$ dilakukan dengan tujuan untuk menguji pengaruh semua variabel independen terhadap variabel dependen. Dengan rumus sebagai berikut: 
Rumus: $\mathrm{F}_{\mathrm{h}}=\frac{\mathrm{R}^{\mathrm{x} / \mathrm{K}-1}}{\frac{1-R^{2}}{\mathrm{n}} / n-K}$

$\mathrm{R}=$ Nilai Koefisien Korelasi; $\mathrm{K}$ $=$ Jumlah Variabel Bebas; $\mathrm{n}=$ Jumlah Sampel; $F_{h} \quad=$ Nilai $F$ yang dihitung

Dengan signifikan sebesar 0,05 , dapat disimpulkan:

1. Jika nilai signifikan $<0,05$ atau $F$ hitung besar dari $\mathrm{F}$ tabel, maka $\mathrm{H}_{\mathrm{o}}$ diterima dan $\mathrm{H}_{\mathrm{a}}$ ditolak artinya tidak terdapat pengaruh yang signifikan antara variabel independen (X) terhadap variabel dependen $(\mathrm{Y})$.

2. Jika nilai signifikan $>0,05$ atau $\mathrm{F}_{\text {hitung }}$ besar dari $\mathrm{F}_{\text {tabel}}$, maka $\mathrm{H}_{\mathrm{o}}$ ditolak, $\mathrm{H}_{\mathrm{a}}$ diterima artinya terdapat pengaruh yang signifikan antara variabel independen (X) terhadap variabel dependen $(\mathrm{Y})$.

\section{HASIL}

Keterbukaan informasi (X1)

Menurut Hapiz (2000:43)

Keterbukaan informasi merupakan keterbukaan pemerintah kepada masyarakat untuk mengakses informasi berdasarkan pertimbangan masyarakat memiliki hak untuk mengetahui secara terbuka dan menyeluruh atas pertanggung jawaban pemerintah tersebut.

Audit Internal (X2)

Menurut Munawir (1996:36) Audit internal adalah suatu fungsi penilaian yang independen yang diterapkan dalam suatu organisasi yang berfungsi untuk menguji dan mengevaluasi kegiatan organisasi sebagai jasa yang diberikan kepada organisasi tersebut. Dengan kata lain, internal audit merupakan pemeriksaan yang dilakukan oleh karyawan perusahaan yang bersangkutan yang disebut akuntan intern yang biasanya tidak terlibat dalam kegiatan pencatatan akuntansi dan kegiatan operasi perusahaan.

Good Corporate Governance (Y)

Menurut I Nyoman Tjager

(dalam Darwati,dkk), (2005:19) Good corporate governance adalah sistem yang mengarahkan dan mengendalikan perusahaan dengan tujuan, agar mencapai keseimbangan antara kekuatan kewenangan yang diperlukan perusahaan, untuk menjamin kelangsungan eksistensinya

pertanggungjawaban kepada stakeholders.

Untuk mengetahui persamaan analisis regresi linier berganda, maka dapat dituliskan sebagai berikut:

$\mathrm{Y}=3,519+0,562 \mathrm{X} 1+0,651 \mathrm{X} 2$

Dengan penjelasan dari persamaan di atas adalah:

1. Nilai dari $\mathrm{a}=3,519$ artinya jika dianggap tidak ada kenaikan nilai dari Keterbukaan Informasi Publik (X1) dan Audit Internal (X2) maka nilai Good Corporate Governance $(Y)$ adalah 3,519 satuan.

2. Koefisien nilai dari Keterbukaan Informasi Publik (X1) bertanda positif artinya menyatakan bahwa dengan meningkatnya

Keterbukaan Informasi Publik akan meningkatkan Good Corporate Governance ( $Y)$.

3. Koefisien nila dari Audit Internal (X2) bertanda positif artinya menyatakan bahwa dengan meningkatnya Audit Internal akan meningkatkan Good Corporate Governance $(Y)$.

\section{SIMPULAN}

Berdasarkan uraian di atas dan analisis bab-bab terdahulu maka dapat di tarik kesimpulan sebagai berikut :

1. Terdapat pengaruh yang signifikan antara Keterbukaan Informasi Publik Terhadap 


\begin{tabular}{|c|c|}
\hline Penerapan & $(2010: 73)$ \\
\hline Governance & operasional audit internal. \\
\hline Daerah Air Minum PDAM Tirta & Nyoman \\
\hline Kerinciyaitu & Darwati,dkk), (2005:19) \\
\hline $\begin{array}{l}\text { dibuktikan dengan thitung }> \\
\text { ttabel }(2,586>2,22814) \quad \text { dan }\end{array}$ & 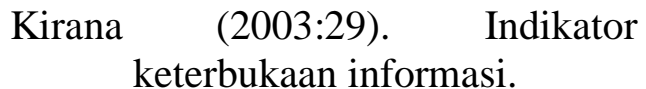 \\
\hline $\begin{array}{l}\text { besarnya pengaruh adalah } 62,7 \% \\
\text { sedangkan sisanya } 37,3 \% \text { dapat }\end{array}$ & $\begin{array}{l}\text { Munawir (1996:36). Jurnal Audit } \\
\text { Internal }\end{array}$ \\
\hline di jelaskan oleh sebab-sebab lain. & Pemenpan \\
\hline pengaruh & PER/05/M.PAN/03/2008 \\
\hline antara Audit Internal & Tentang Standar Audit Aparat \\
\hline Penerapan & Pengawasan \\
\hline Governance & Pemerintah. \\
\hline
\end{tabular}

Perusahaan Daerah Air Minum PDAM Tirta Sakti Kerinciyaitu dapat dibuktikan dengan thitung $>$ ttabel $(2,648>2,22814)$ dan besarnya pengaruh adalah $38,6 \%$ Sedangkan sisanya $61,4 \%$ dapat di jelaskan oleh sebab-sebab lain.

3. Terdapat pengaruh yang signifikan antara Keterbukaan Informasi Publik Dan Audit Internal Terhadap Penerapan Good Corporate Governance Pada Perusahaan Daerah Air Minum PDAM Tirta Sakti Kerinciyaitu dapat dibuktikan dengan Fhitung > Ftabel $(8,272>$ 4,26) dan besarnya pengaruh adalah $64,8 \%$. Sedangkan sisanya $35,2 \%$ dapat di jelaskan oleh sebab-sebab lain.

\section{DAFTAR PUSTAKA}

Agoes, Sukrisno (2011). Petunjuk Praktis Pemeriksaan Akuntan oleh Akuntan Publik, Jakarta.

Arens,Alvin A, Elder,Randal J, Mark S. Beasley (2010).Auditing and Assurance

Arthur W. Holmes dalam Buku Auditing Norma dan Prosedur Auditi..

Daniri, Mas Achmad. 2005. Good Corporate Governance. Konsep dan penerapannya dalam

Sawyer (2002:10) Auditing Internal

STIE-SAK,. 2012. Pedoman Penulisan dan Penyusuanan Skripsi . Sungai Penuh- Jambi

Valery G.2011. Internal Audit. Jakarta : Erlangga

Zarkasyi. 2008. Cetakan Kesatu. Good Corvorate Governance pada Badan Usaha 